(2) Open Access Full Text Article

\title{
Pentacam-based phototherapeutic keratectomy outcome in superficial corneal opacities
}

This article was published in the following Dove Press journal:

Clinical Ophthalmology

13 June 2012

Number of times this article has been viewed

\author{
Mohammad A Rashad \\ Ophthalmology Department, Faculty \\ of Medicine, Ain Shams University, \\ Cairo, Egypt
}

Purpose: This study aimed to evaluate the effectiveness of phototherapeutic keratectomy (PTK) as an alternative treatment to keratoplasty using the Pentacam to assess depth of dense opacities.

Methodology: PTK was performed in eleven eyes of ten patients with superficial corneal opacities after assessment by Scheimpflug images of the Pentacam for central corneal thickness (CCT) and opacity level and depth.

Results: The best-corrected spectacle visual acuity (BCSVA) significantly improved. The preoperative mean logMAR was 0.85 ( 0.14 decimal equivalent, 6/42 Snellen's equivalent), and the final postoperative mean $\log$ MAR was 0.58 ( 0.26 decimal equivalent, 6/23 Snellen's equivalent). The mean preoperative CCT was $465.64 \pm 71.94 \mu \mathrm{m}$. The mean programmed ablation depth was $142.09 \pm 47.58 \mu \mathrm{m}$. The programmed ablation depth was correlated to mean $\log$ MAR early ( 1 month) and not correlated later (6 months). None of the eyes lost lines of BCSVA or developed serious complications, such as keratectasia, delayed epithelialization, or corneal melting.

Conclusion: Corneal scars extending beyond the anterior one-fifth of the cornea can be treated safely and effectively by PTK due to the smoothing effect, with reduction of the cylinder rather than complete opacity removal. This can decrease the need for keratoplasty.

Keywords: phototherapeutic keratectomy, PTK, corneal opacities, Pentacam

\section{Introduction}

The $193 \mathrm{~nm}$ wavelength of the excimer laser has made it possible to perform very precise corneal surgery. The system was developed for refractive surgery as photorefractive keratectomy (PRK) and laser-assisted in situ keratomileusis (LASIK). ${ }^{1}$

Phototherapeutic keratectomy (PTK) is an important excimer laser-based surgical tool for treatment of numerous corneal disorders, such as superficial dystrophies and scars. ${ }^{2}$ PTK was also reported to be effective in recurrent corneal erosions, ${ }^{3}$ and Salzmann nodular degeneration. ${ }^{4}$ The aim of the procedure should not only be to increase corneal clarity but also to decrease surface irregularities, which contributes to improved vision. Transepithelial PTK has been described to utilize the epithelium as a masking agent to fill microscopic irregularities on the corneal surface. .,6 $^{5}$

We tried to evaluate PTK after epithelial debridement as an alternative to penetrating keratoplasty in the treatment of anterior corneal opacities, considering both opacities and irregularities.
Correspondence: Mohammad Ahmad Rashad

Ophthalmology Department, Faculty of Medicine, Ain Shams University, Cairo, Egypt

Tel +20I 223463327

Emailmahmadr@yahoo.com 


\section{Methodology}

\section{Inclusion criteria}

- Superficial corneal opacity

- PKP not suitable or carrying high risk

\section{Exclusion criteria}

- Lenticular opacity

- Retinal disease

- Glaucoma

- Previous laser surgery

- Corneal thickness $<400$ um

- Deep corneal opacity

- Recurrent corneal erosions

- Corneal dystrophies

All cases of corneal disease that underwent PTK from 2007 to 2011 were reviewed retrospectively from medical records. Details were noted regarding preoperative full history and ophthalmological examination, including visual acuity (VA), intraocular pressure (IOP), retinal evaluation, and, if possible, spherical equivalent refraction with best-corrected visual acuity (BCVA).

Informed consent was obtained from all patients. A detailed slit-lamp microscopy was performed with particular attention to the corneal surface and depth of the lesion.

These parameters were assessed before examination and at postoperative visits. It mainly focused on laser PTK as an alternative to PKP in their superficial opacities including the possibility of need to PKP in case of unsatisfactory vision or ectasia development. This was especially enforced in eyes with opacities extending beyond anterior one fifth as case no 6 (Figures 1-4).

Preoperative assessment of central corneal thickness (CCT) by ultrasound was performed in all cases. A Pentacam
Scheimpflug examination using a WaveLight Allegro Oculyzer $^{\mathrm{TM}}$ (WaveLight AG, Erlangen, Germany) was also performed to ensure thickness assessment. In addition, a Pentacam examination using a density map was used to assess the level and depth of the opacity and to exclude lenticular opacity (Figures 1, 3 and 5).

As topical anesthesia, proparacaine eye drops were administered to all patients. The opacity diameter was measured by caliber to define the treatment zone. An excimer laser (Allegretto; WaveLight) was used for an ablation zone of $5 \mathrm{~mm}$ to $7 \mathrm{~mm}$. Q 400 was used in all eyes.

Mechanical debridement of the corneal epithelium was performed by dry microsponge. Resistant epithelium attachment overlying some opacity was removed by a sharp Beaver blade.

Carboxymethyl cellulose $1 \%$ was applied as a film over the irregular corneal surface to avoid irregular ablation. The carboxymethyl cellulose film was spread by a weak jet of balanced salt solution (BSS; Alcon ${ }^{\circledR}$, Fort Worth, TX) to make the film thinner.

Repeated ablation was performed 2 to 5 times until the opacity appeared less dense. One session's ablation depth was $50 \mu \mathrm{m}$. Slit-lamp microscopy was performed whenever it was needed between sessions to ensure nearly complete removal of opacities and to avoid thinning caused by repeated ablations.

As a masking agent, carboxymethyl cellulose $1 \%$ was spread on the corneal surface before every ablation session.

It was noted that each PTK session removed part of the opacity when the masking agent fluorescence began to regress.

At the conclusion of surgery, a bandage contact lens (CL) was applied. A postoperative slit-lamp examination was

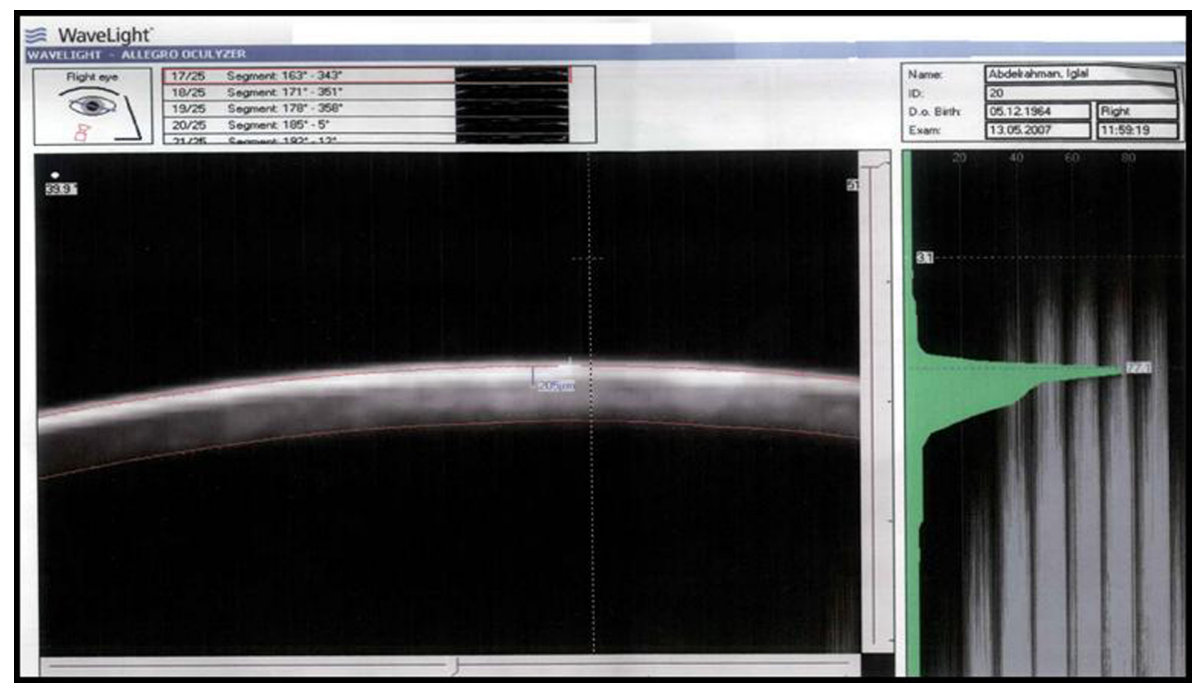

Figure I Case no 6. Preoperative Pentacam opacity measurement: segment $163^{\circ}-343^{\circ}$. 


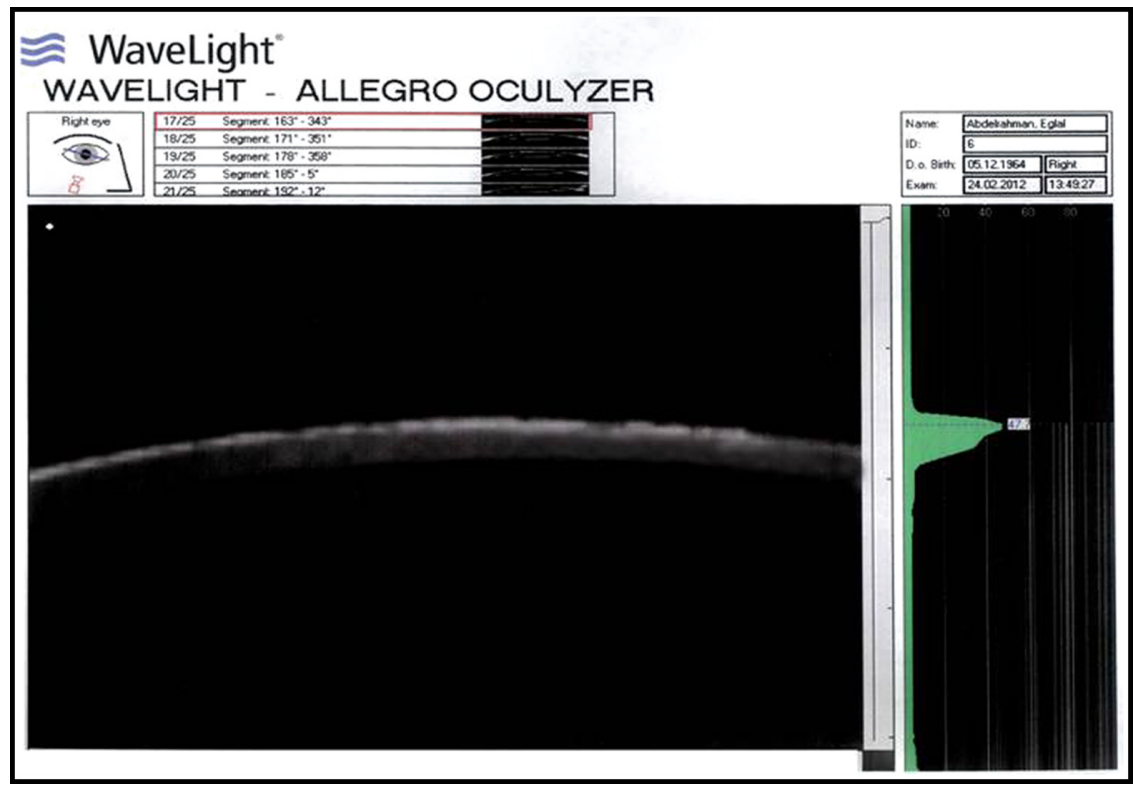

Figure 2 Case no 6. Postoperative Pentacam opacity: measurement segment $163^{\circ}-343^{\circ}$ with marked reduction of opacity.

performed immediately. Postoperative treatment consisted of ofloxacin $0.3 \%$ every 2 hours in the first 3 days, reduced to 6 times per day for another 3 days, and TobraDex (Alcon) every 12 hours until epithelium healing was complete. It then was increased to 6 times per day for 3 days. Ofloxacin $0.3 \%$ was stopped abruptly, and TobraDex was withdrawn gradually over 3 weeks. Preservative-free Refresh Plus ${ }^{\circledR}$ (Allergan, Irvine, CA) eye drops were used regularly every 4 hours for the first month, then whenever needed for the following 3 months postoperatively. Patients were followed up at 1 day, 3 days, 1 week, 1 month, 3 months, and 6 months.
The minimum follow-up period was 6 months, and the longest follow up period was 3 years. The mean follow-up period was 18.2 months ( \pm 6.1 months).

The main outcome measures included indications for the procedure, severity of postoperative pain, healing time, best-corrected spectacle visual acuity (BCSVA), complications, number of sessions, and ablation depth.

\section{Statistical methods}

The qualitative data are presented as numbers and percentages, and the quantitative data are presented as mean \pm standard

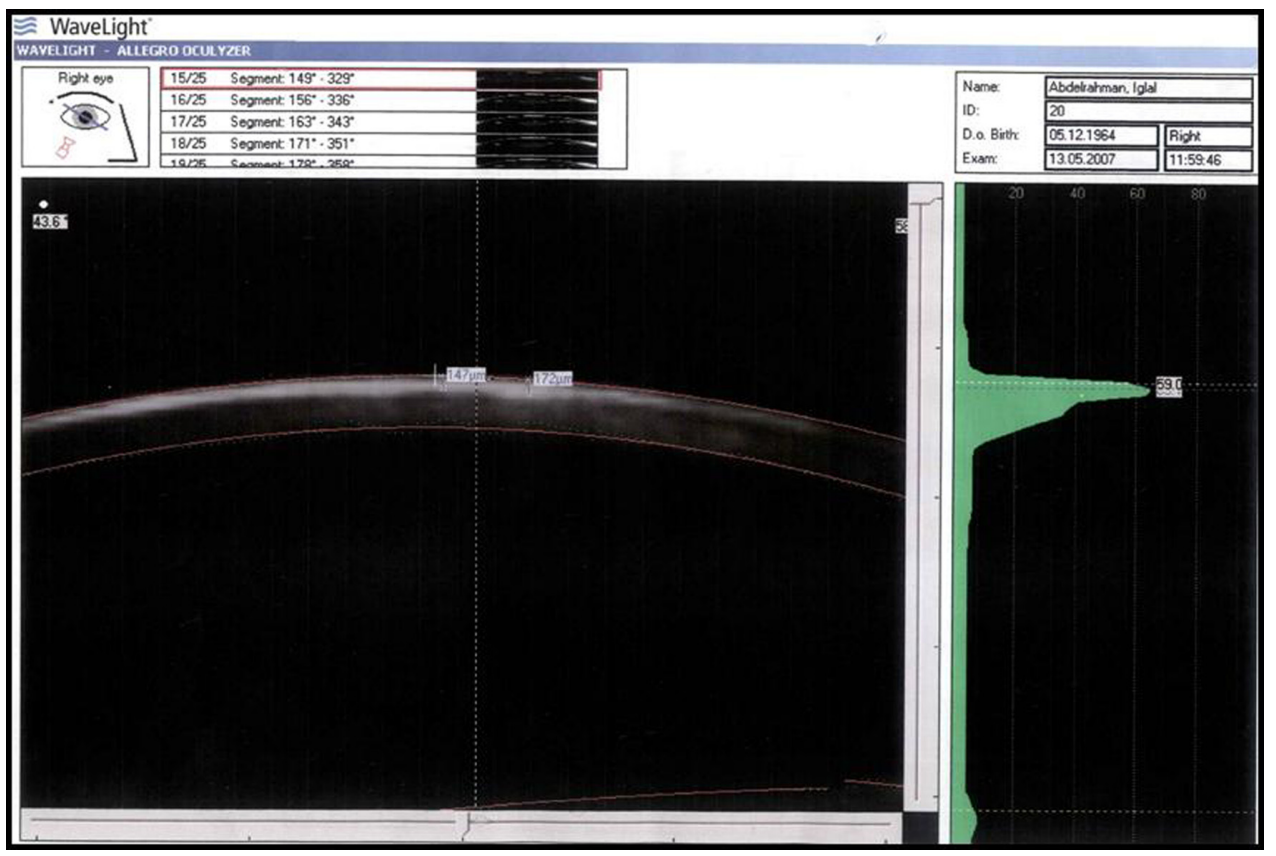

Figure 3 Case no 6. Preoperative Pentacam opacity measurement: segment $149^{\circ}-329^{\circ}$ 


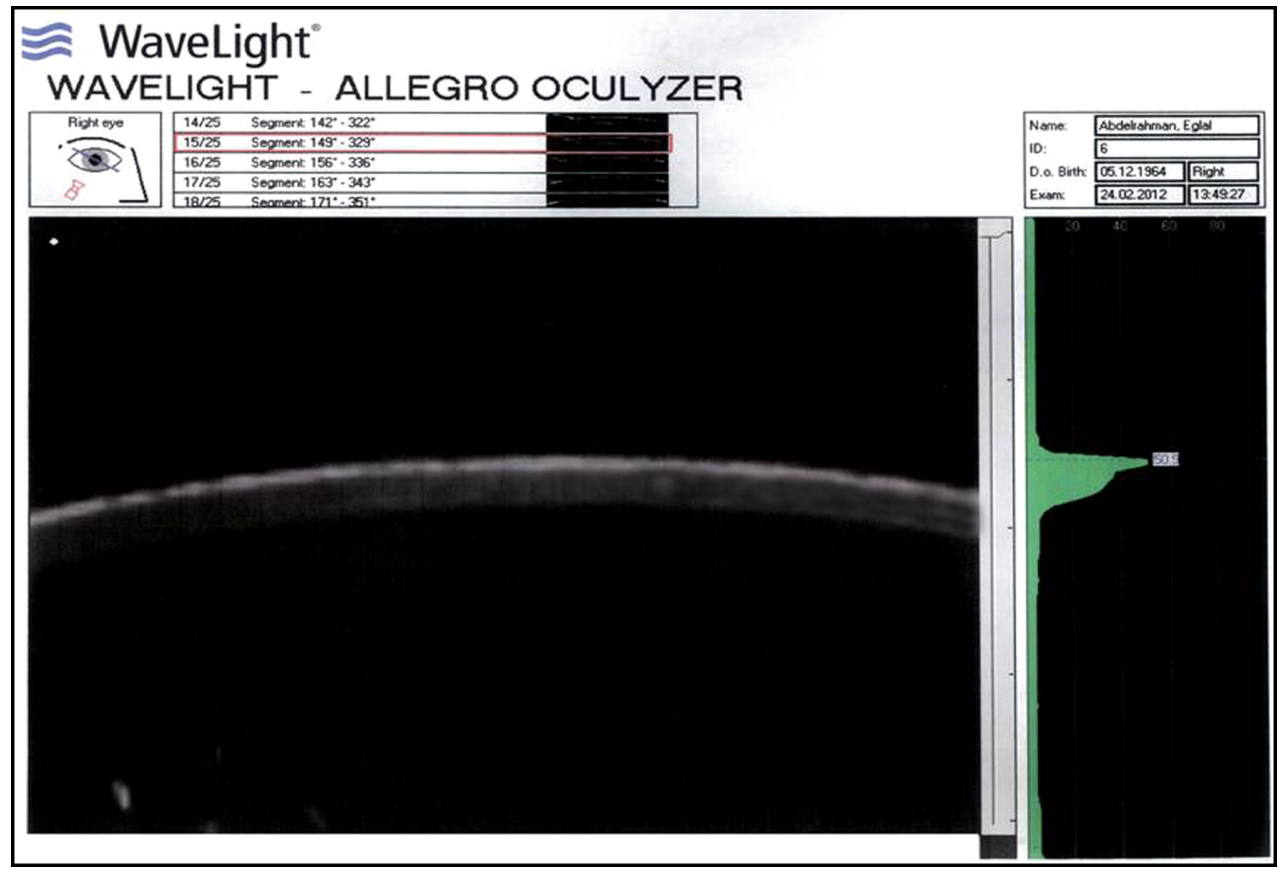

Figure 4 Case no 6. Postoperative Pentacam opacity measurement: segment $149^{\circ}-329^{\circ}$ with marked reduction of opacity.

deviation. The data were analyzed using a paired $t$-test to compare preoperative and postoperative parametric data, and a Wilcoxon test for nonparametric data. A Pearson correlation coefficient was used to assess the relation between the study parameters. The $P$-value was considered significant at $<0.05$.

\section{Results}

\section{Preoperative patient characteristics}

Eleven eyes in 10 patients were operated on. The mean age was (42.55 years). Four eyes were in males $(36.36 \%)$ and seven eyes were in females (63.63\%). Indications for PTK in all eyes were superficial corneal scars of different etiologies. Five eyes had unknown etiology, three eyes had previous corneal ulcer, two eyes had corneal degeneration, and one eye had postsurgical scaring after pterygium surgery. The mean preoperative CCT was $465.64 \pm 71.94$ (Table 1).

\section{Operative data}

The mean programmed ablation depth was $142.09 \pm 47.58$, the mean number of ablation sessions was $2.64 \pm 1.36$ (Table 2).

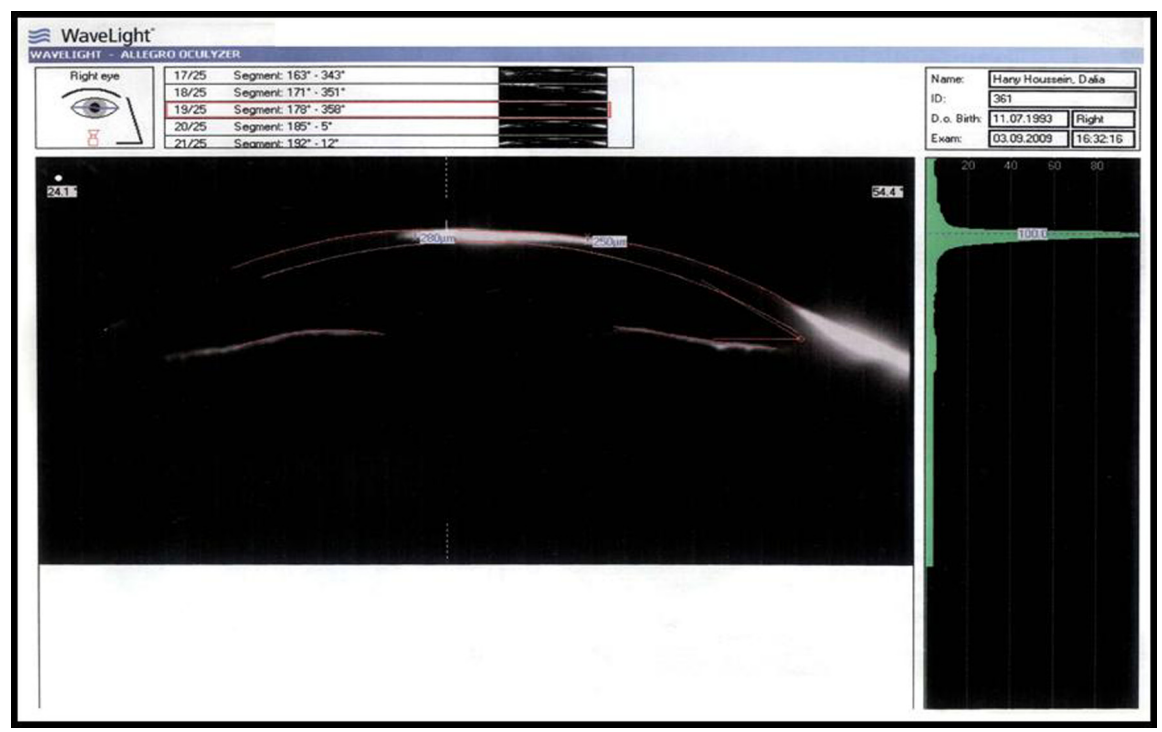

Figure 5 Case no 8. Preoperative Pentacam opacity measurement: segment $178^{\circ}-353^{\circ}$. 
Table I Preoperative characteristics

\begin{tabular}{lll}
\hline & No & Percentage \\
\hline Indications & & \\
$\quad$ Unknown & 5 & $45.45 \%$ \\
Postulcer scar & 3 & $27.27 \%$ \\
Corneal degeneration & 2 & $18.19 \%$ \\
$\quad$ Postpterygium surgery & 1 & $9.09 \%$ \\
Central corneal thickness $(\mu \mathrm{m})$ & & \\
$400-500$ & 7 & $63.63 \%$ \\
$500-600$ & 4 & $36.36 \%$ \\
\hline
\end{tabular}

\section{Early postoperative period}

Epithelial healing was achieved after $3.55 \pm 0.52$ days. Maximum time for epithelial healing was 4 days. Mean duration of pain following the procedure was $1.55 \pm 0.52$ days (Table 2 ).

\section{BCSVA}

The mean preoperative $\log$ MAR was $0.85 \pm 0.36$ ( 0.14 decimal equivalent, 6/42 Snellen's equivalent). There was significant improvement from baseline logMAR to postoperative logMAR of $0.58 \pm 0.327$ (0.26 decimal equivalent, 6/23 Snellen's equivalent) at 1 month and $0.58 \pm 0.39$ at 6 months (Table 3 and Figure 6). Improved VA was satisfactory in all patients.

There was a significant positive correlation between programmed ablation depth and postoperative mean $\log \mathrm{MAR}$ at 1 month $(P=0.029 ; \mathrm{r}=0.655)$. There was no correlation between programmed ablation depth and postoperative mean $\log M A R$ at 6 months $(P=0.168 ; \mathrm{r}=0.447)$ (Table 4 and Figure 7$)$. There was no significant relation found between preoperative CCT and postoperative results mean logMAR (Table 5).

At the last postoperative visit, the BCSVA was $>0.5$ (6/12 Snellen's equivalent) in three eyes (27\%), 0.2-0.4 (6/30-6/15 Snellen's equivalent) in six eyes (55\%), and 0.05 in two eyes (18\%). None of the eyes achieved 0.6-1.0 BCSVA at the last postoperative visit. None of the eyes lost lines of BCSVA.

\section{Refractive change}

Changes in manifest refraction spherical equivalents (MRSE) were variable. The mean MRSE changed from

Table 2 Descriptive for operative and postoperative data

\begin{tabular}{lllll}
\hline & Minimum & Maximum & Mean & $\begin{array}{l}\text { Standard } \\
\text { deviation }\end{array}$ \\
\hline $\begin{array}{l}\text { Programmed ablation } \\
\text { depth }(\mu \mathrm{m})\end{array}$ & 70 & 300 & 142.09 & 74.58 \\
$\begin{array}{l}\text { Sessions } \\
\begin{array}{l}\text { Duration of pain } \\
\text { (days) }\end{array}\end{array}$ & 2 & 5 & & \\
$\begin{array}{l}\text { Healing time } \\
\text { (days) }\end{array}$ & 3 & 2 & 1.55 & 0.52 \\
\hline
\end{tabular}

Table 3 Comparison between preoperative and postoperative mean logMAR

\begin{tabular}{lclcc}
\hline LogMAR & Mean & $\begin{array}{l}\text { Standard } \\
\text { deviation }\end{array}$ & $\boldsymbol{t}$ value & $\mathbf{P}$ value \\
\hline Preoperative & 0.85 & 0.36 & 3.207 & $0.009 * *$ \\
Postoperative (I month) & 0.58 & 0.32 & & \\
Preoperative visual acuity & 0.85 & 0.36 & 2.318 & $0.043 *$ \\
Postoperative (6 months) & 0.58 & 0.39 & & \\
\hline Notes: $* P<0.05$, statistically significant difference; $* * P<0.0$, highly statistically \\
significant difference.
\end{tabular}

-4.17 diopter (D) preoperatively to $+0.75 \mathrm{D}$ postoperatively at 6 months, which was not statistically significant (Table 6). Myopic shift was found in 2/11 eyes (18\%) and hyperopic shift was found in $8 / 11$ eyes $(82 \%)$. There was hyperopic shift from emmetropia to +2.25 and in case no 6 (Figures 8 and 9) and from $-14.50 \mathrm{D}$ to $+2.50 \mathrm{D}$ in case no 8 (Figures 10 and 11). Significant postoperative residual refractive error was corrected by contact lenses in $18 \%$ of eyes and by glasses in $82 \%$ of eyes.

The retrospective nature of the study did not allow postoperative Pentacam in all cases. Postoperative Pentacam Scheimpflug images showed evident reduction of corneal opacity in case no 6 (Figures 1-4, 8 and 9) and evident reduction of astigmatism in case no 8 (Figures 5, 10-12).

\section{Postoperative complications}

Mild stromal haze was reported in 3/11 eyes (27\%). None of the patients had recurrence of opacities during the follow up time. None of the eyes developed keratectasia, even those with long periods of follow up. Residual stromal opacities were noticed in 5/11 eyes (45\%), which did not affect patient satisfaction. Improvement of VA was satisfactory in all patients.

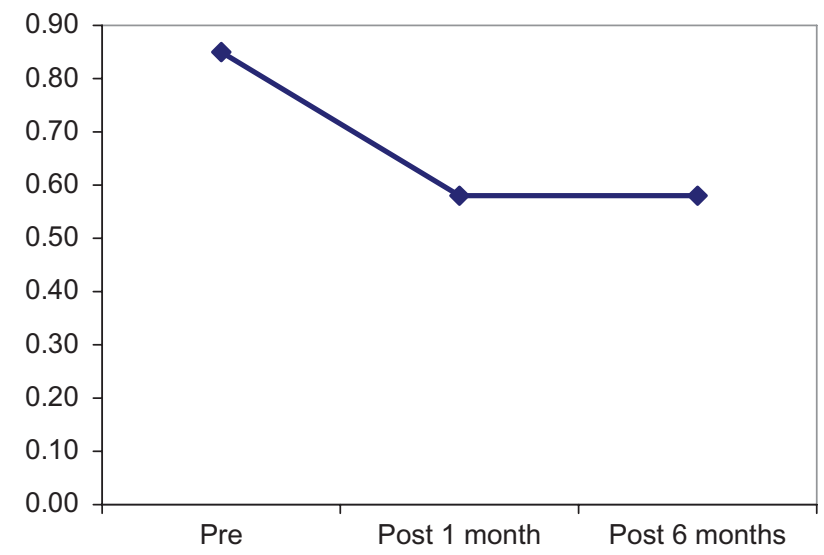

Figure 6 Improvement of mean logMAR. 
Table 4 Correlation between programmed ablation and postoperative mean logMAR at I month and 6 months

\begin{tabular}{lll}
\hline Mean logMAR & \multicolumn{2}{l}{ Programmed ablation $(\mu \mathrm{m})$} \\
\cline { 2 - 3 } & $\mathbf{r}$ & $\boldsymbol{P}$ \\
\hline Postoperative (I month) & $0.655^{*}$ & 0.029 \\
Postoperative (6 months) & 0.447 & 0.168 \\
\hline
\end{tabular}

Note: *Correlation is significant.

Abbreviation: $r$, correlation coefficient.

\section{Discussion}

Photoablation removes corneal tissue with minimal alteration of adjacent corneal lamellae. ${ }^{1}$ Removal of diseased corneal tissue with an excimer laser used in PTK has the potential to improve visual function. ${ }^{7,8}$ Disorders treated with PTK included superficial corneal scars or irregularities, corneal degeneration, corneal dystrophies, and recurrent corneal erosions. We used the Pentacam to ensure CCT measurement and opacity depth and level. Lackner et $\mathrm{al}^{9}$ stated that Pentacam reproducibility of CCT measurements was highest among ultrasound, Orbscan, and Pentacam. Similarly, Riss et $\mathrm{al}^{10}$ successfully used Pentacam-based deep anterior lamellar keratoplasty. They used Pentacam in preoperative pachymetry for an intended depth of trephination at $90 \%$. A useful objective measurement of mild corneal haze using a density map was described. ${ }^{11}$

Eyes were excluded according to the following criteria: corneal dystrophies because of reported temporary effects and high recurrence rates; ${ }^{2,8}$ recurrent corneal erosion because of very successful outcomes both pathologically and visually, ${ }^{12}$ which would lead to biased outcomes if included together with corneas having superficial opacities; retinal or optic nerve disease to define visual gain; lenticular opacities proved by Scheimpflug Pentacam examination. Scheimpflug

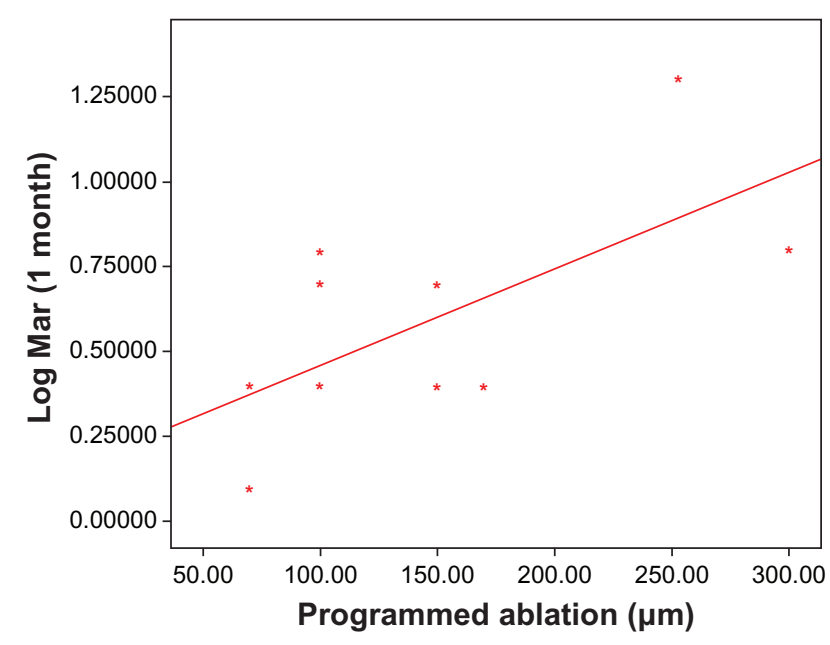

Figure 7 Correlation between programmed ablation $(\mu \mathrm{m})$ and postoperative mean logMAR at I month.
Table 5 Correlation between programmed ablation depth and I month and 6 months postoperative mean logMAR

\begin{tabular}{lll}
\hline Mean logMAR & $\begin{array}{l}\text { Central corneal } \\
\text { thickness }(\mu \mathrm{m})\end{array}$ \\
\cline { 2 - 3 } & $\mathbf{r}$ & $\mathbf{P}$ \\
\hline Postoperative (I month) & 0.181 & 0.593 \\
Postoperative (6 months) & 0.086 & 0.80 I \\
\hline Abbreviation: $r$, correlation coefficient & &
\end{tabular}

Pentacam images present an objective and repeatable method for assessment of cataract density, which could be helpful in longitudinal studies. ${ }^{13}$

We included eyes with corneal thickness of at least $400 \mu \mathrm{m}$, in which PTK was a primary alternative to PKP. This is especially suitable for the circumstances in our country, which has limited availability of donor corneal tissue. This is supported by the proposed benefit of PTK for corneas with opacities extending beyond anterior one-fifth because entire removal of opacity is not often necessary to achieve visual improvement. ${ }^{7}$

Similarly, Alio et al described removal of opacities deeper than anterior one-fifth of the cornea. ${ }^{14}$ They removed anterior corneal opacities after assessment by confocal microscopy. They removed $335 \mu \mathrm{m}$ opacity from $610 \mu \mathrm{m}$ corneal thickness (55\% of corneal tissue), $290 \mu \mathrm{m}$ opacity from 538 corneal thickness (54\% of corneal tissue), and $120 \mu \mathrm{m}$ opacity from 408 corneal thickness ( $30 \%$ of corneal tissue). However, none of these eyes developed corneal ectasia.

Similarly, none of our eyes developed keratectasia during the follow-up time despite having started with a mean CCT of $465 \mu \mathrm{m}$ and using repeated ablation sessions. The explanation is that we used carboxymethyl cellulose film in each session, thus reducing the depth of the treatment. ${ }^{15}$ The result was smoothing rather than thinning of the cornea.

No correlation was found between preoperative CCT and postoperative mean $\log \mathrm{MAR}$ at 1- and 6-month visits. Thus, PTK was equally effective in fair thickness as well as thin corneas. One clear consequence of this procedure is the induction of corneal thinning, which requires prolonged follow up because of its biomechanical effects.

Our patients were informed that PTK is used as an alternative to PKP with uncertain results over time. PKP is known to be associated with prolonged rehabilitation, risk of rejection, and highly irregular astigmatism. ${ }^{16}$

Scarred corneas may have different architecture and behavior due to changes in the collagen arrangement, which might be a reason for stability despite thinning. Furthermore, measurement of the corneal thickness may be not accurate in scarred cornea. This was seen in case no 8 where thinnest 
Table 6 Comparison between pre and postoperative MRSE

\begin{tabular}{lllllll}
\hline & Minimum & Maximum & Mean & Standard deviation & $\mathbf{z}$ & $\mathbf{P}$ value \\
\hline Preoperative refraction & -16 & 4 & -4.17 & 7.25 & -2.136 \\
Postoperative refraction & -4.5 & 3.75 & 0.75 & 2.87 & 0.065 \\
\hline
\end{tabular}

Abbreviations: MRSE, manifest refraction spherical equivalents; $z$, Wilcoxon value.

preoperative location was $429 \mu \mathrm{m}$. The thinnest postoperative location was $397 \mu \mathrm{m}$ despite decreased opacity (Figures 5,10-12).

We used carboxymethyl cellulose rather than epithelium as a coupling agent because scarred cornea may have very irregular epithelium and grossly irregular stromal surface. ${ }^{7}$ Therefore, we used carboxymethyl cellulose many times to smooth the surface before every ablation session. PTK improves the visual function by reducing rather than eliminating corneal opacity if associated with smoothing of the anterior corneal surface. ${ }^{7}$ This explains the significant improvement of BCSVA although $45 \%$ of eyes had residual stromal opacity. The technique of using carboxymethyl cellulose $1 \%$ was similarly described for elevated corneal opacities in corneal dystrophies as a masking agent for irregularities. ${ }^{17}$

An epithelial healing time of $3.55 \pm 0.52$ days was similar to van Westenbrugge's results. ${ }^{18}$ Dogru et al ${ }^{15}$ reported smoothing of the corneal surface by PTK. It was also reported that smoothing of the corneal surface after PTK results in stability of the tear film and break-up time, ${ }^{19}$ which may improve VA. Moreover, postoperatively, a smooth surface avoids irregular astigmatism after lamellar corneal surgery. ${ }^{20}$ This explained the improvement of BCSVA despite the incomplete opacity removal.

There was a significant correlation between programmed ablation depth and postoperative mean $\log$ MAR at 1 month, which indicated that increased ablation depth was associated with better $\log$ MAR. This might be because of more opacity removal resulting from more ablation. There was no correlation between ablation depth and logMAR at 6-month follow up, which is probably because of the epithelium remodeling and surface smoothing that occurred in the time interval. This surface smoothing resulted in compensation for any residual opacity effect on vision. Case no 8 showed reduction of astigmatism from $18.2 \mathrm{D}$ to $2.6 \mathrm{D}$, which denotes a smoothing effect (Figures 10 and 11). However, Figures 5 and 12 show incomplete removal of opacity.

Alio et $\mathrm{al}^{21}$ described lamellar keratectomy by automated microkeratome adjusted according to opacity depth established by confocal microscope. However, they used sodium hyaluronate $0.25 \%$ (coupling agent) assisted PTK to smooth the surface.

In our study, the mean final postoperative $\log$ MAR was 0.52 ( 0.3 decimal equivalent). This result differed from Al-Afraj et $\mathrm{al}^{19}$ and Alio et $\mathrm{al}^{14}$ who reported 0.6 decimal equivalent, postoperatively. This difference could be explained by their better starting baseline decimal equivalents, which was 0.4 in both studies. The starting baseline decimal equivalent in our study was 0.16 .

Another explanation is the inclusion criteria of Al-Afraj et $\mathrm{al},{ }^{19}$ who included eyes with recurrent corneal erosion, whereas the present study included only eyes with corneal opacities. Moreover, Alio et a ${ }^{14}$ used microkeratome automated

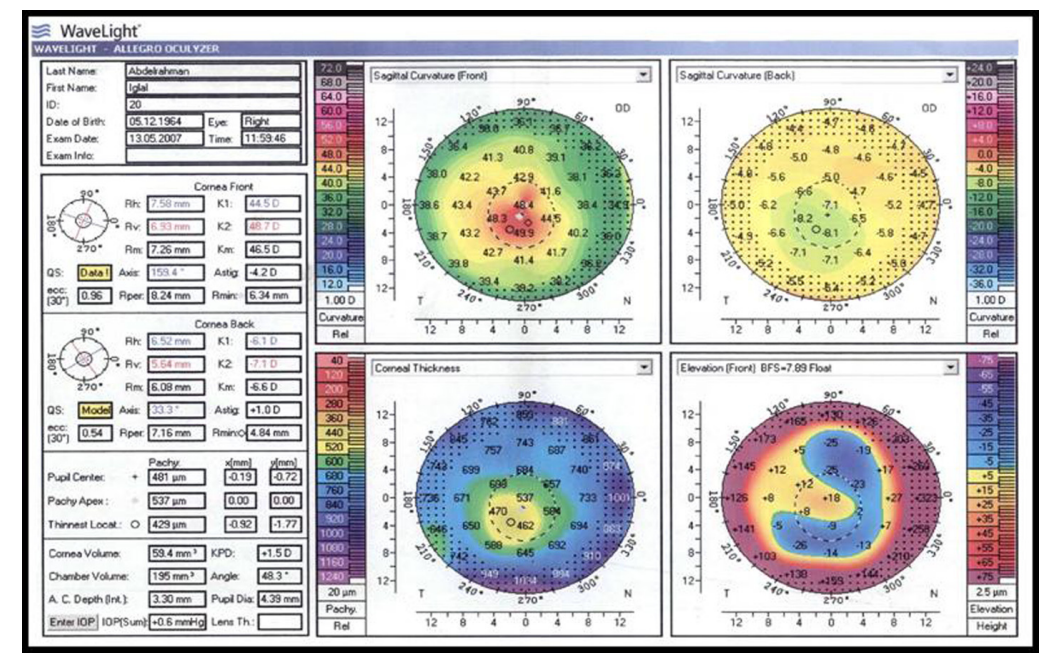

Figure 8 Case no 6. Preoperative Pentacam 4 map. 


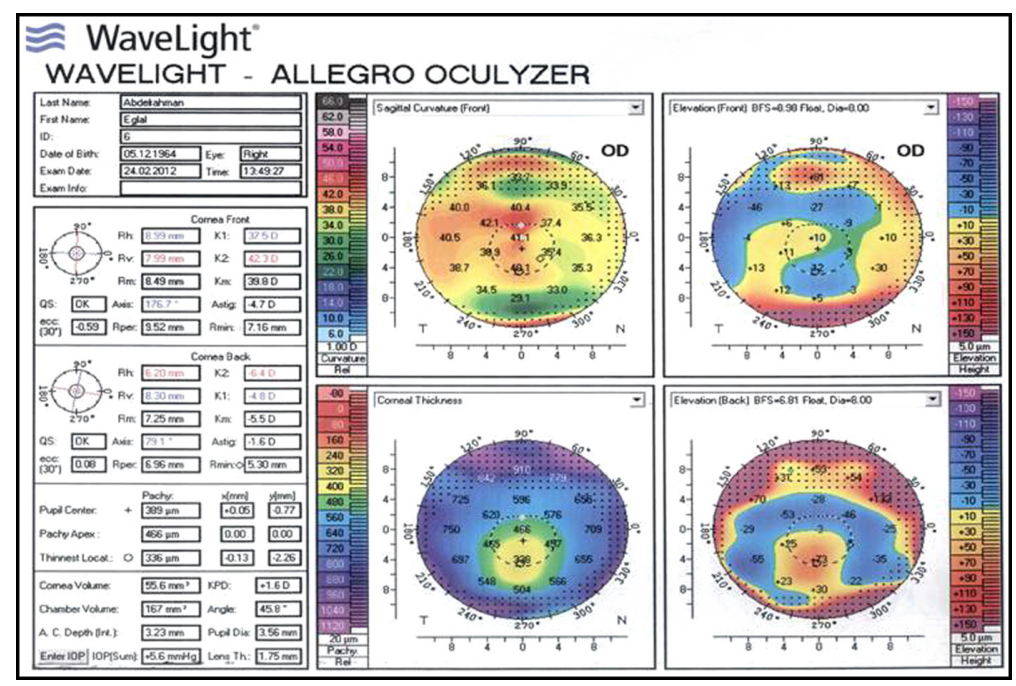

Figure 9 Case no 6. Postoperative Pentacam 4 map.

superficial keratectomy augmented by hyaluronic acid-assisted PTK, which removed all opacity. The present study removed less corneal tissue and therefore less opacity.

Regarding lines of improvement by decimal notation, our eyes improved about two lines from 0.13 to 0.2 . Similarly, an improvement of 2 lines from 0.4 to 0.6 was found in Alio et al's study. ${ }^{14}$ Another study ${ }^{21}$ reported an improvement of 2-3 lines improvement although it used femtosecond laserassisted superficial lamellar keratectomy, which creates a more regular cut. However, hyaluronate-assisted PTK was used to smooth the bed further.

In our study, $27 \%$ of eyes achieved $>0.5$ BCSVA, $55 \%$ of eyes had BCSVA of 0.2-0.4, and no eyes achieved 0.6-1.0. These results differ from Muller et al, who reported uncorrected visual acuity of 0.5 or better in $70 \%$ of eyes ${ }^{5}$ and BCSVA of 1.0 in $60 \%$ of eyes. ${ }^{6}$ The results in our study differed because Muller et al used a PTK-PRK mode, probably because thickness allowed it. Our mean CCT was $465 \mu \mathrm{m}$, which did not permit PRK-PTK. Furthermore, relatively dense opacities in our studies did not allow proper refraction to perform PRK with PTK.

Our eyes had variable postoperative MRSE, which could be explained by variable depths of ablation because of opacity depth and variable treatment zones according to opacity diameters.

Fagerholm ${ }^{20}$ reported that plano treatment influenced refraction according to depth of ablation and diameter of optical zone. They also reported that using a masking agent might alter the degree of refractive change. We used a

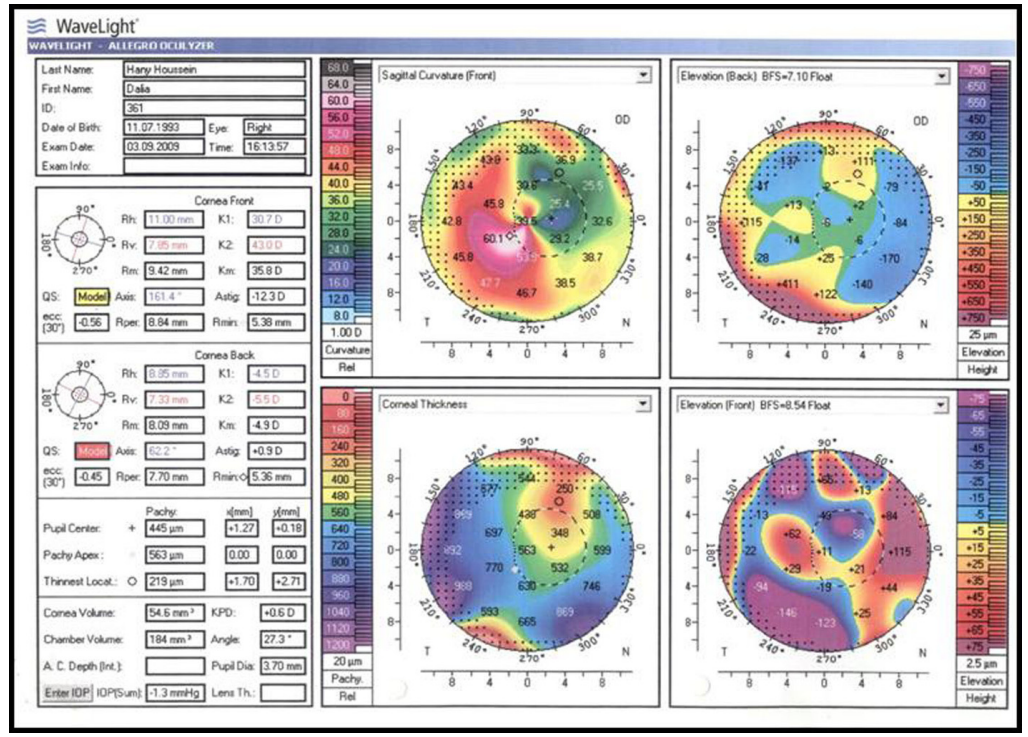

Figure 10 Case no 8. Preoperative Pentacam with preoperative astigmatism of -18.2 D. 


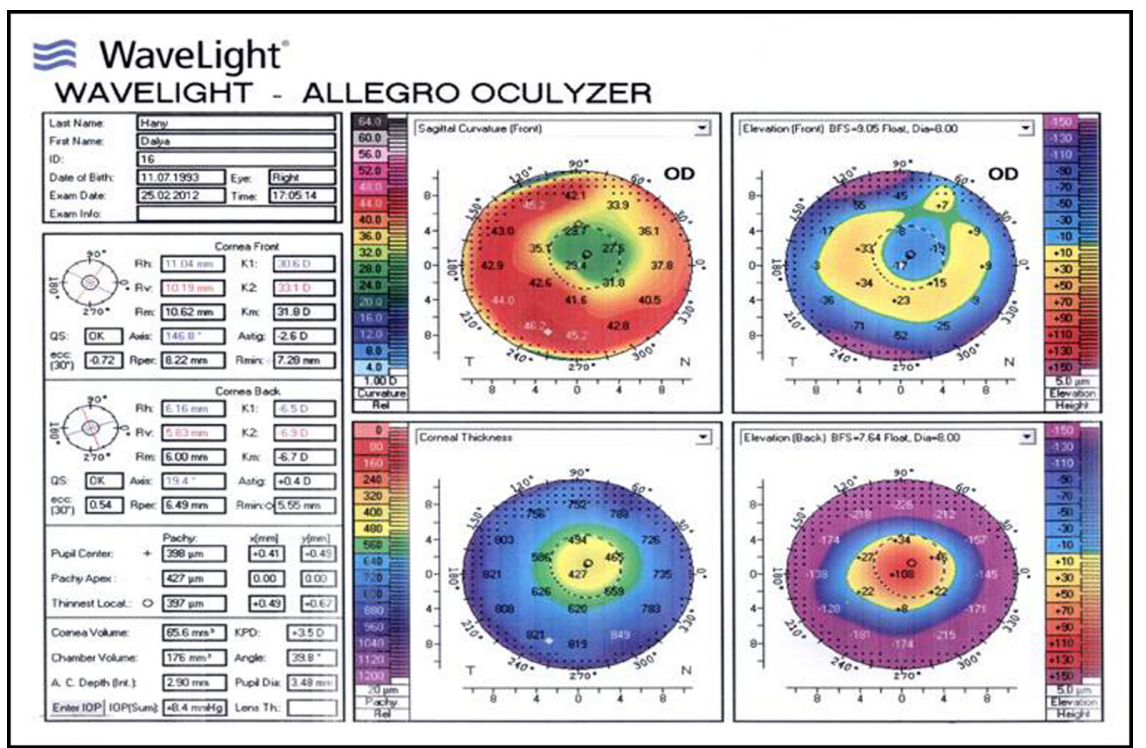

Figure I I Case no 8. Postoperative Pentacam 4 map with marked reduction of astigmatism of $-2.6 \mathrm{D}$.

coupling agent 2 to 5 times per case during ablation, which might have resulted in variable refractive change. Similar to our study, Al-Afraj et a $1^{19}$ reported variable refractive change with hyperopic shift in $33 \%$ of eyes and myopic shift in $17 \%$ of eyes. They also explained that epithelial remodeling and inaccuracy of preoperative refraction due to corneal opacification might be responsible for this variability.
Mild stromal haze was found in $27 \%$ of eyes in our study. This result differed from Al-Afraj et al, ${ }^{19}$ who reported mild stromal haze in $55 \%$ of eyes. This difference is probably because of the inclusion criteria in our study (corneal opacities), whereas Al-Afraj et a $\mathrm{a}^{19}$ included corneal dystrophies characterized by recurrences.

Another explanation for less haze is that we used carboxymethyl cellulose to smooth the surface, which

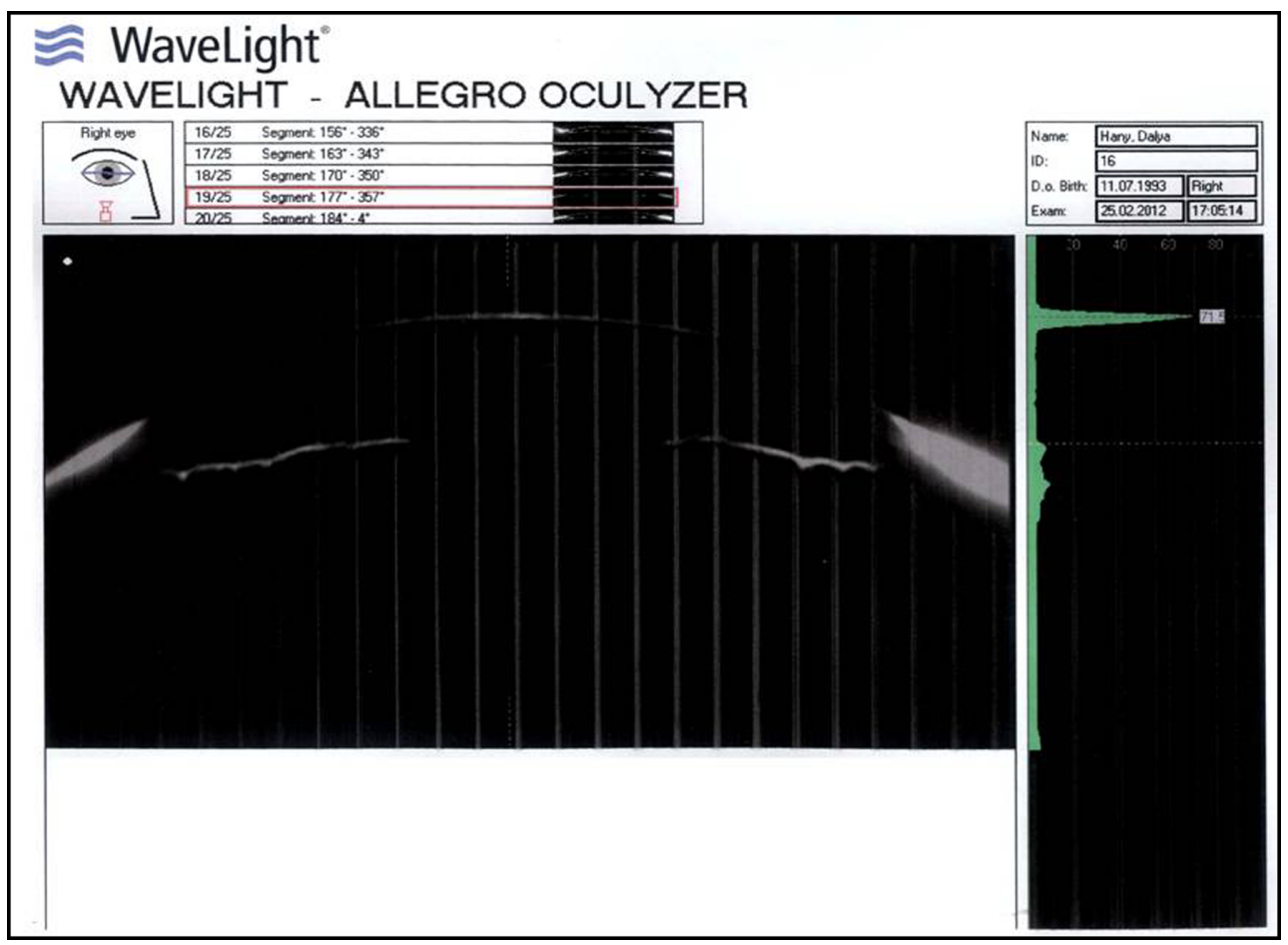

Figure 12 Case no 8. Postoperative Pentacam opacity measurement: segment $178^{\circ}-353^{\circ}$. 
decreases the probability of postoperative haze. On the other hand, Al Afraj et al ${ }^{19}$ used transepithelial PTK.

None of our patients had recurrence of opacity. This result differed from Hanfer et $\mathrm{al}^{2}$ who reported that $60 \%$ of their eyes needed keratoplasty. This difference can be explained by the inclusion of dystrophic corneas by Hanfer et al.

\section{Conclusion}

PTK can be considered a safe procedure with minimal side effects. Improvement of BCSVA can be achieved in eyes with anterior corneal opacities even beyond anterior one-fifth and in thin corneas. This result depends on smoothing the corneal surface instead of full elimination of opacity, which can help cancel or delay the need for PKP.

\section{Disclosure}

The author reports no conflicts of interest.

\section{References}

1. Stark WJ, Chamon W, Kamp MT. Clinical follow up of $193 \mathrm{~nm} \mathrm{ArF}$ excimer laser photokeratectomy. Ophthalmology. 1992;99:805.

2. Hanfer A, Langenbueher A, Satz B. Long term results of phototherapeutic keratectomy for macular corneal dystrophy. Am J Ophthalmol. 2005;140: 392-396.

3. van Westenbrugge JA. Small spot phototherapeutic keratectomy for recurrent corneal erosion. J Refract Surg. 2007;23:721-724.

4. Germundsson J, Fagerholm P. Phototherapeutic keratectomy in Salzmann's nodular degeneration. Acta Ophthalmol Scand. 2004;82: 148-153.

5. Muller LT, Candal EM, Epstein RJ, Dennis RF, Majimudar PA. Transepithelial phototherapeutic keratectomy/photorefractive keratectomy with adjunctive mitomycin C for complicated LASIK flaps. J Cataract Refract Surg. 2005;31(2):291-296.

6. Buzzonetti L, Petrocelli G, Laborante A, et al. A new transepithelial phototherapeutic keratectomy mode using the NIDEK C XIII excimer laser. J Refract Surg. 2009;25(1):S122-S124.

7. Trudo EW, Stark WJ, Azar DT. Phototherapeutic keratectomy. In: Kaufman HE, Barron BA, McDonald MB, editors. The Cornea. Boston, MA: Butterworth-Heinemann; 1998:749-759.
8. Wagner MD, Badr IA. Phototherapeutic keratectomy for macular corneal dystrophy. J Refract Surg. 1999;15:481-484.

9. Lackner B, Schmidinger G, Pieh S, Funovics MA, Skorpik C. Repeatability and reproducibility of central corneal thickness measurement with Pentacam, Orbscan, and ultrasound. Optom Vis Sci. 2005;82(10):892-899.

10. Riss S, Heindl LM, Bachmann BO, Kruse FE, Crusiefen C. Pentacam-bused big bubble deep anterior lamellar keratoplasty in patients with keratoconus. Cornea. February 21, 2012 [Epub ahead of print.]

11. Takacs AI, Mihaltz K, Nagy ZZ. Corneal density with the Pentacam after photorefractive keratectomy. J Refract Surg. 2011;27(4):269-277.

12. Das S, Seitz B. Recurrent corneal erosion syndrome. Surv Ophthalmol. 2008;53:3-15.

13. Grewal DS, Brar GS, Grewal SP. Correlation of nuclear cataract lens density using Scheimpflug images with Lens Opacities Classification System III and visual function. Ophthalmology. 2009;116(8): $1436-1443$

14. Alio JL, Javaloy J, Merayo J, Galal A. Automated superficial lamellar keratectomy augmented by excimer laser masked PTK in the management of severe superficial corneal opacities. Br J Ophthalmol. 2004;88: 1289-1294.

15. Dogru M, Katakami C, Miyashita M. Ocular surface changes after excimer laser phototherapeutic keratectomy. Ophthalmology. 2000;107: 1144-1152.

16. Koay PYP, McGhee CNJ, Weed KH. Laser in situ keratomileusis for ametropia after penetrating keratoplasty. J Refract Surg. 2000;16: 140-147.

17. Khoury JM, Salti H, El-Haibi C, Noureddin B. Modified phototherapeutic keratectomy technique for treatment of elevated corneal opacities. Ophthalmic Surg Lasers Imaging. 2009;40:203-206.

18. van Westenbrugge JA. Small spot phototherapeutic keratectomy for recurrent corneal erosion. J Refract Surg. 2007;23:721-724.

19. Al-Afraj K, Jain V, Hantera M, et al. Phototherapeutic keratectomy outcomes in superficial corneal opacities. Ophthalmology and Eye Diseases. 2011;3:1-6.

20. Fagerholm P. Phototherapeutic keratectomy: 12 years of experience. Acta Ophthalmol Scand. 2003;81:9-32.

21. Alio JL, Agdeppa MC, Uceda-Montanes A. Femtosecond laser-assisted superficial lamellar keratectomy for treatment of superficial corneal leukomas. Cornea. 2011;30:301-307.
Clinical Ophthalmology

\section{Publish your work in this journal}

Clinical Ophthalmology is an international, peer-reviewed journal covering all subspecialties within ophthalmology. Key topics include: Optometry; Visual science; Pharmacology and drug therapy in eye diseases; Basic Sciences; Primary and Secondary eye care; Patient Safety and Quality of Care Improvements. This journal is indexed on Submit your manuscript here: http://www.dovepress.com/clinical-ophthalmology-journal

\section{Dovepress}

PubMed Central and CAS, and is the official journal of The Society of Clinical Ophthalmology (SCO). The manuscript management system is completely online and includes a very quick and fair peer-review system, which is all easy to use. Visit http://www.dovepress.com/ testimonials.php to read real quotes from published authors. 